\title{
Comparative efficacy of Belzer or Euro-Collins solutions for pancreatic preservation during cold ischemic storage in rats ${ }^{1}$
}

\author{
Rogério Renato Perez ${ }^{\text {I, Alberto Goldenberg }}$, Alcides Augusto Salzedas Netto ${ }^{\text {III }}$, Adriano Miziara Gonzalez ${ }^{\text {IV }}$ \\ IFellow Master degree, Postgraduate Program in Interdisciplinary Surgical Sciences, Sao Paulo Federal University(UNIFESP), Sao Paulo-SP, Brazil. \\ Surgical procedures, acquisition and interpretation of data, manuscript writing. \\ IIPhD, Associate Professor, Gastroenterological Surgery Division, Department of Surgery, Paulista School of Medicine (EPM), UNIFESP, Sao Paulo- \\ SP, Brazil. Interpretation of data.

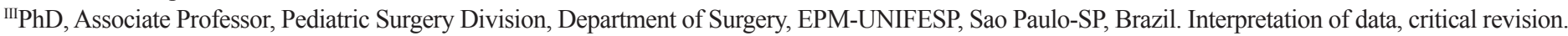 \\ ${ }^{\text {IV }} \mathrm{PhD}$, Associate Professor, Gastroenterological Surgery Division, Liver and Pancreas Transplant Unit, Department of Surgery, EPM-UNIFESP, Sao \\ Paulo-SP, Brazil. Conception and design of the study, manuscript writing, critical revision.
}

\section{ABSTRACT}

PURPOSE: To compare the efficacy of different types of solutions (Belzer or Euro-Collins) for the preservation of rat pancreas during cold ischemia.

METHODS: Thirty Wistar rats were divided into three groups according to the perfusion or storage solution: Group E (perfusion and storage in Euro-Collins solution); Group B (perfusion and storage in Belzer solution) and Group BE (Perfusion in Belzer solution and storage in Euro-Collins solution). After perfusion, the pancreas was excised and stored at $4^{\circ} \mathrm{C}$ for 18 hours. Amylase was measured at 6 , 12 and 18h, and histological analysis of the pancreas was performed after $18 \mathrm{~h}$ of cold storage.

RESULTS: Amylase was elevated and comparable in Groups E and BE after 12 and 18 hours of ischemia $(\mathrm{p}<0.05)$. In the exocrine pancreas, histological differences in the amount of necrosis $(\mathrm{p}=0.049)$, lymphocytic infiltrate $(\mathrm{p}<0.001)$ and neutrophilic infiltrate $(\mathrm{p}=0.004)$ were observed, with more favorable features present in Group B. In the endocrine pancreas, Group B showed less edema $(\mathrm{p}<0.001)$, but other parameters were similar among all groups.

CONCLUSION: The Euro-Collins solution is inferior to the Belzer solution for the preservation of rat pancreas during cold ischemia. Key words: Diabetes Mellitus, Type 1. Islets of Langerhans Transplantation. Organ Preservation Solutions. Rats. 


\section{Introduction}

Type I diabetes is caused by an autoimmune reaction direct against pancreatic beta cells in Langerhans islets, leading to lifelong exogenous insulin dependence. Its prevalence is estimated to be around one million cases in Brazil ${ }^{1}$, and the age of diagnosis peaks between eight and 12 years. Seven new cases are expected for 100,000 persons per year, but this incidence is increasing $3 \%$ annually. Half of these patients may develop severe damage to target organs, leading to loss in quality of life and restricting socioeconomic activities ${ }^{1}$. Conventional medical treatments with exogenous insulin prolong overall survival in diabetic patients, but do not control progression of chronic lesions in the long run ${ }^{2}$.

William Kelly and Richard I. Lillehei performed the first successful kidney-pancreas transplant in 1966, demonstrating the feasibility of glycemic control without exogenous insulin ${ }^{3}$. Medical and technical advances in immunosuppressant drugs, surgical techniques and selection criteria for receptors and donors culminated in prolonged survival for these patients ${ }^{4}$. The kidneypancreas transplant promotes perfect glycemic control and avoids progression of chronic lesion in target organs ${ }^{5}$. Such results lead the American Diabetes Association to accept the kidney-pancreas transplant as the treatment of choice for diabetic patients with endstage renal-failure ${ }^{6}$.

Crystalloid solutions, such as the Euro-Collins solution, were initially used for preservation of the organ after extraction until the late 1980s, but were later shown to be inferior to a more complex solution, such as Belzer's ${ }^{7,8}$. Others have shown that a crystalloid solution and the Belzer solution may be used sequentially for the cold perfusion and storage stages ${ }^{9,10}$.

The average cost of a kidney-pancreas transplant in Brazil is US\$ 20,000.00, including donor selection and hospitalization procedures $^{1}$, which may increase US\$ $15,000.00$ more in case of surgical complications ${ }^{11}$. Supplies, including storage solutions, account for $36 \%$ of that amount in our institution. The Belzer solution is ten times more expensive than the Euro-Collins solution (US\$ 400.00 versus US\$ 40.00 per liter) at our institution, and three liters are necessary for each transplant. Reducing costs by using a less expensive storage solution may, therefore, have a large impact promoting the use of kidney-pancreas transplant as a viable choice for diabetic patients with end-stage renal impairment.

\section{Methods}

Research approved by the Ethic Committee of Sao Paulo Federal University (CEP 1501-11) and followed the Council for
International Organization of Medical Sciences (CIOMS) ethical code for animal experimentation ${ }^{13}$.

Thirty female Wistar rats, three to four months old, were divided into three groups (10 rats per group) according to perfusion and storage solutions. In Group E, the pancreas was flushed and preserved with the Euro-Collins solution (Fresenius Kabi Brazil Ltda). In Group BE, the pancreas was flushed with the Belzer solution ${ }^{12}$ and stored in Euro-Collins solution. In Group B, the whole procedure was performed with the Belzer solution.

\section{Surgical procedures}

Animals were kept without food 12 hours prior to surgery, which was performed by the same surgeon (R.R.P.) at the Development Experimental Models for Medicine and Biology (CEDEME), UNIFESP. On the day of surgery, the animals were weighed and anesthetized with a combination of $20 \%$ ketamine and $80 \%$ xylazine, $0.1 \mathrm{ml} / 100 \mathrm{~g}$ animal weight, intraperitoneally. The animal was positioned dorsally, contained by its four members. Asepsis was achieved with 70\% ethanol.

The abdominal cavity was exposed by longitudinal section, and the duodenum was identified and ligated with a cotton 2-0 suture, right after the pylorus and at the duodenal-jejunal transition. The abdominal aorta was identified and dissected, and a 4-0-cotton suture positioned below the renal arteries. The right renal vein was injected with $0.1 \mathrm{ml}$ of heparin with a 23 needle. After 1 minute, the infra-renal aorta was punctured with a $22 \mathrm{G}$ Jelco $^{\circledR}$ catheter, which was affixed with a 4-0 cotton suture.

A median thoracotomy was performed at this point, and the thoracic aorta was clamped close to the diaphragm. The thoracic inferior vena cava was sectioned to drain blood and perfusate. Perfusion with $20 \mathrm{ml}$ of flushing solution at $4{ }^{\circ} \mathrm{C}$ (EuroCollins or Belzer) was initiated and maintained for 8 minutes, using a Samtronic, ST 670 model infusion pump (Samtronic Infusion Systems, Sao Paulo, Brazil), with a $150 \mathrm{ml} /$ hour infusion rate. Pancreas, duodenum and spleen were then dissected and maintained for $18 \mathrm{~h}$ in $20 \mathrm{ml}$ of the selected storage solution in a closed storage flask.

\section{Amylase detection}

At six, 12 and 18 hours of storage, $2 \mathrm{ml}$ of storage fluid was collected in an Eppendorf tube and sent under refrigeration to Provet Moema Veterinary Clinic, Sao Paulo, Brazil. Amylase measurement was performed using a Vitros 250 Chemical Analyzer amylopectin kit (Johnson\&Johnson, Brazil). 


\section{Histological analysis}

After $18 \mathrm{~h}$ in cold storage fluid, the dissected organs were fixated in $10 \%$ formaldehyde. The pancreas was separated from the duodenum and spleen and included in paraffin. Longitudinal $5 \mu \mathrm{m}$ microtome cuts were performed and stained on glass slides with hematoxylin-eosin.

One veterinary pathologist at Provet Moema Veterinary Clinic, blinded for the assigned groups, was responsible for evaluating the histological parameters, using the classification described by Smith et al. ${ }^{14}$ and later updated by Mayer et al. ${ }^{15}$. The exocrine and endocrine pancreas were evaluated separately for each parameter (edema, neutrophilic infiltrate, lymphocytic infiltrate, necrosis, apoptosis and vascular thrombosis) using a score of zero for absent, 1 for mild, 2 for moderate and 3 for severe.

\section{Statistical analysis}

Variables were described as mean, median, minimum and maximum values, standard deviation, and absolute and relative frequency. Inferential analysis was done using one-way ANOVA for weight and repeated-measures ANOVA, with the Tukey posttest, for amylase values at different times (6,12 and 18h). The Kruskal-Wallis test was used for comparison of histological parameters. The level of significance $\alpha$ was set at $5 \%$.

Excel 2010for Windows ${ }^{\circledR}$ was used for storing data, and statistical analyses were performed using Statistica v.12 for Windows ${ }^{\circledR}$ and R v.2.15.2.

\section{Results}

\section{Animal weight}

Results are shown in Table 1. Mean animal weight varied between 191 and 193g. There was no statistical difference among groups $(\mathrm{p}=0.961)$.

TABLE 1 - Animal weight for each group in grams (g).

\begin{tabular}{cccccc}
\hline Group* & Mean & Median & Min.Value & $\begin{array}{c}\text { Max. } \\
\text { Value }\end{array}$ & SD \\
\hline B & 193.0 & 190.0 & 170.0 & 230.0 & 19.5 \\
\hline BE & 191.0 & 190.0 & 170.0 & 220.0 & 16.6 \\
\hline E & 193.0 & 190.0 & 170.0 & 230.0 & 18.9 \\
\hline
\end{tabular}

Group B, Belzer solution for perfusion and storage

Group BE, Belzer solution for perfusion, Euro-Collins solution for storage

Group E, Euro-Collins solution for perfusion and storage

\section{Amylase}

Amylase was collected from the storage solution six, 12 and $18 \mathrm{~h}$ after placement of surgical specimen in the solution. A statistically significant interaction between time and amylase levels was observed $(\mathrm{p}<0.001)$, indicating that a difference was detected in amylase levels both when comparing groups and time.

After 12 and 18h, results from Group B showed lower amylase levels than either Group BE or Group E; furthermore, amylase levels did not change significantly during the storage period in Group B. Results are presented in Table 2. Meaningful statistical comparisons are presented in Table 3.

TABLE 2 - Amylase levels (UI/L).

\begin{tabular}{ccccccc}
\hline & Groups & Mean & Median & Min. & Max. & SD \\
\hline $6 \mathrm{~h}$ & & & & & & \\
\hline & B & 43.8 & 32.5 & 29.0 & 76.0 & 18.7 \\
& BE & 219.2 & 182.5 & 54.0 & 459.0 & 130.2 \\
& E & 201.9 & 185.0 & 44.0 & 491.0 & 137.6 \\
\hline $12 \mathrm{~h}$ & & & & & & \\
\hline & B & 74.9 & 70.5 & 29.0 & 182.0 & 47.1 \\
& BE & 356.4 & 272.5 & 133.0 & 635.0 & 176.3 \\
& E & 315.6 & 280.5 & 94.0 & 701.0 & 193.3 \\
\hline $18 \mathrm{~h}$ & & & & & & \\
\hline & B & 113.7 & 108.0 & 35.0 & 214.0 & 60.7 \\
& BE & 514.7 & 489.0 & 265.0 & 827.0 & 207.3 \\
& E & 426.9 & 379.0 & 134.0 & 834.0 & 223.7 \\
\hline
\end{tabular}

Group B, Belzer solution for perfusion and storage

Group BE, Belzer solution for perfusion, Euro-Collins solution for storage Group E, Euro-Collins solution for perfusion and storage

TABLE 3 - Statistical analysis among groups and time for amylase values.

\begin{tabular}{ccc}
\hline Type of comparison & Conclusions & p value** \\
\hline Group B & 6 hours $=12$ hours & 0.88 \\
& 6 hours $=18$ hours & 0.052 \\
& 12 hours $=18$ hours & 0,69 \\
\hline Group BE & 6 hours $<12$ hours & $<0.001$ \\
& 6 hours $<18$ hours & $<0.001$ \\
& 12 hours $<18$ hours & $<0.001$ \\
\hline Group E & 6 hours $<12$ hours & $<0.001$ \\
& 6 hours $<18$ hours & $<0.001$ \\
& 12 hours $<18$ hours & $<0.001$ \\
\hline 6 hours & Group B $=$ Group BE & 0.224 \\
& Group B $=$ Group E & 0.345 \\
& Group BE $=$ Group E & $>0.999$ \\
\hline
\end{tabular}




\begin{tabular}{ccc}
\hline 12 hours & Group B $<$ Group BE & 0.006 \\
& Group B $<$ Group E & 0.028 \\
& Group BE = Group E & 0.999 \\
\hline 18 hours & Group B $<$ Group SB & $<0.001$ \\
& Group B $<$ Group E & $<0.001$ \\
& Group BE = Group E & 0.922 \\
\hline
\end{tabular}

$\overline{\text { Group B, Belzer solution for perfusion and storage. Group BE, Belzer solution for }}$ perfusion, Euro-Collins solution for storage. Group E, Euro-Collins solution for perfusion and storage. ${ }^{* *}$ Tukey post-test.

\section{Histological analysis}

Histological parameters were evaluated according to grade of severity (see Methods). For the exocrine pancreas, there were significant differences in the amount of necrosis $(p=0.049)$, neutrophilic infiltrate $(\mathrm{p}=0.004)$ and lymphocytic infiltrate $(\mathrm{p}<0.001)$, all favoring Group B. There was no difference in the amount of edema among groups $(\mathrm{p}=0.368)$. No apoptosis or vascular thrombosis could be detected in any group (data not shown). Results are detailed in Table 4, and some examples are shown in Figure 1.

TABLE 4 - Histological parameters analysis for the exocrine pancreas, relative frequency $(\%)$.

\begin{tabular}{|c|c|c|c|c|c|}
\hline & Group & B & $\mathrm{BE}$ & $\mathrm{E}$ & $\mathrm{p}^{* *}$ \\
\hline \multirow[t]{5}{*}{ Edema } & & & & & 0.368 \\
\hline & absent & 0 & 0 & 0 & \\
\hline & mild & 90 & 100 & 100 & \\
\hline & moderate & 0 & 0 & 0 & \\
\hline & severe & 0 & 0 & 0 & \\
\hline \multirow[t]{5}{*}{ Necrosis } & & & & & 0.049 \\
\hline & absent & 100 & 90 & 60 & \\
\hline & mild & 0 & 10 & 40 & \\
\hline & moderate & 0 & 0 & 0 & \\
\hline & severe & 0 & 0 & 0 & \\
\hline \multirow{5}{*}{$\begin{array}{l}\text { Neutrophilic } \\
\text { Infiltrate }\end{array}$} & & & & & 0.004 \\
\hline & absent & 50 & 0 & 10 & \\
\hline & mild & 50 & 50 & 40 & \\
\hline & moderate & 0 & 40 & 50 & \\
\hline & severe & 0 & 10 & 0 & \\
\hline \multirow{4}{*}{$\begin{array}{l}\text { Lymphocytic } \\
\text { Infiltrate }\end{array}$} & & & & & $<0.001$ \\
\hline & absent & 80 & 0 & 10 & \\
\hline & mild & 20 & 100 & 80 & \\
\hline & $\begin{array}{r}\text { moderate } \\
\text { severe }\end{array}$ & 0 & 0 & 10 & \\
\hline
\end{tabular}

$\overline{\text { Group B, Belzer solution for perfusion and storage. Group BE, Bel- }}$ zer solution for perfusion, Euro-Collins solution for storage. Group E, Euro-Collins solution for perfusion and storage. **Kruskal-Wallis test.

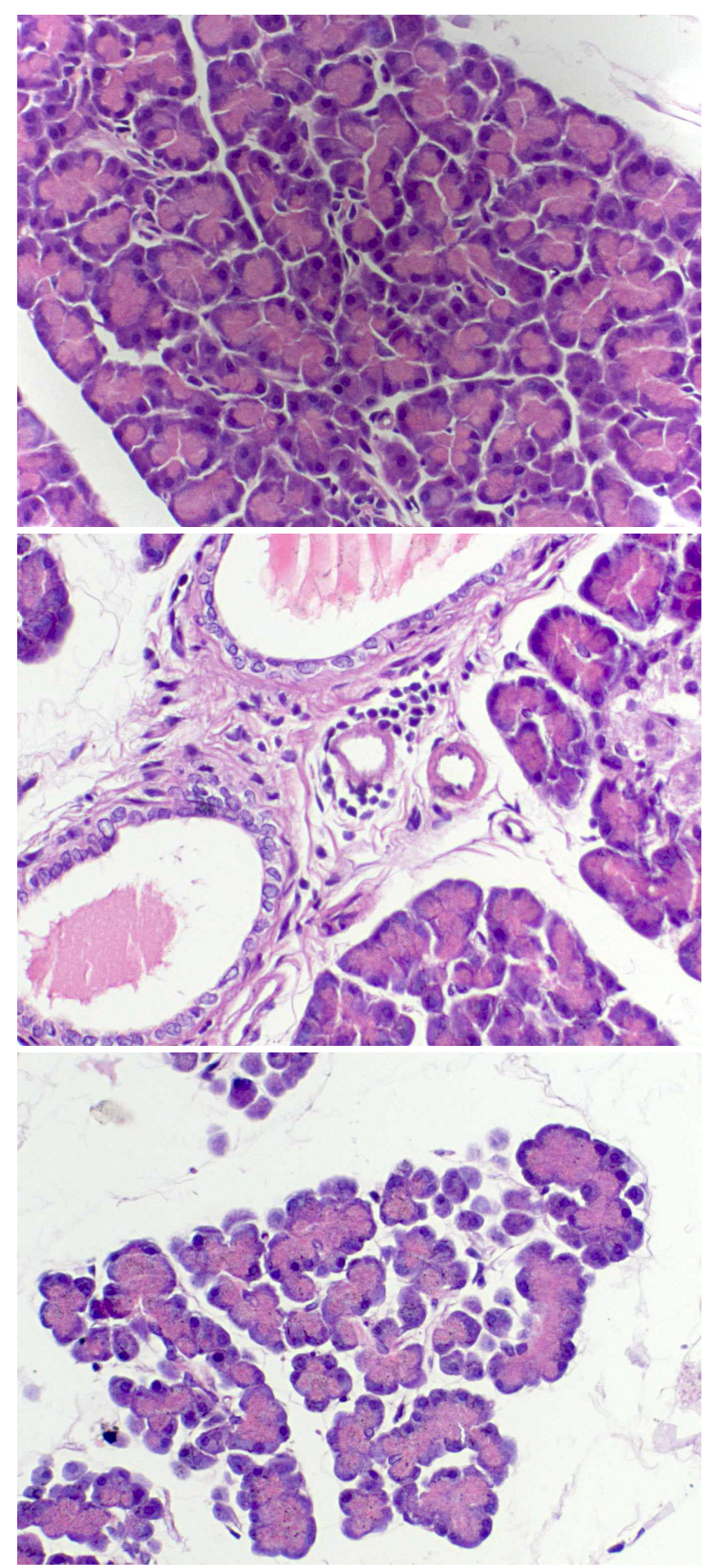

FIGURE 1 - Exocrine pancreas photomicrographs, HE staining, x200. A. Group B, normal glandular architecture. B. Perivascular lymphocytic infiltrate, Group BE. C. Mild necrosis and neutrophilic infiltrate, Group E.

For the endocrine pancreas, there were significant differences only in the amount of edema $(p<0.001)$ with a much lower severity in Group B. There were no differences in necrosis or lymphocytic infiltrates among groups $(\mathrm{p}=\mathrm{ns})$. No neutrophilic infiltrate, apoptosis or vascular thrombosis could be detected in any group (data not shown). Results are detailed in Table 5 and example shown in Figure 2. 
TABLE 5 - Histological parameters analysis for the endocrine pancreas, relative frequency $(\%)$.

\begin{tabular}{lrllll}
\hline Group & $\mathrm{B}$ & $\mathrm{BE}$ & $\mathrm{E}$ & $\mathrm{p}$ \\
\hline Edema & & & & & $<0.001$ \\
absent & 20 & 0 & 0 & \\
mild & 60 & 0 & 0 & \\
moderate & 20 & 30 & 100 & \\
severe & 0 & 70 & 0 & \\
\hline Necrosis & & & & & 0.595 \\
absent & 100 & 90 & 90 & \\
mild & 0 & 0 & 10 & \\
moderate & 0 & 10 & 0 & \\
severe & 0 & 0 & 0 & \\
\hline Lymphocytic Infiltrate & & & & & 0.342 \\
& absent & 100 & 90 & 80 & \\
mild & 0 & 0 & 20 & \\
moderate & 0 & 10 & 0 & \\
severe & 0 & 0 & 0 &
\end{tabular}

Group B, Belzer solution for perfusion and storage. Group BE, Belzer solution for perfusion, Euro-Collins solution for storage. Group E, Euro-Collins solution for perfusion and storage.**Kruskal-Wallis test.

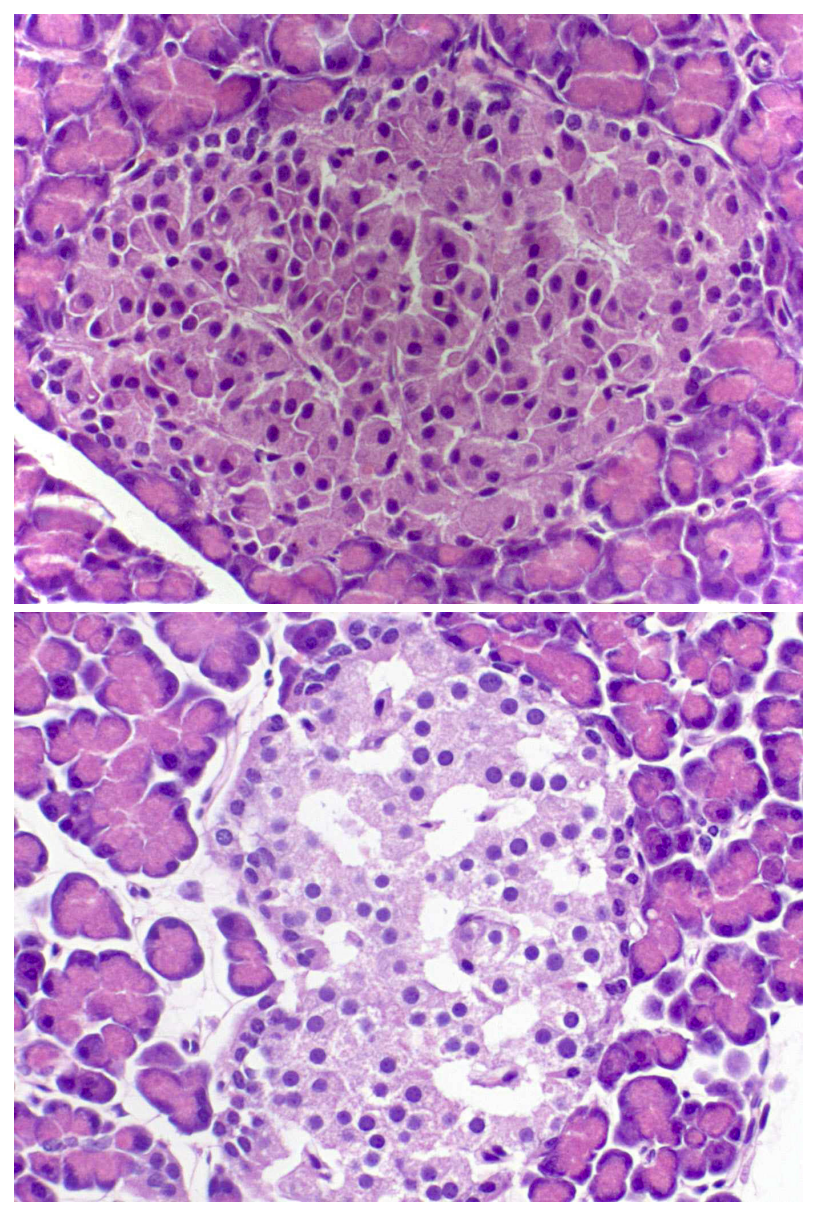

FIGURE 2 - Endocrine pancreas photomicrographs, HE staining, x400. A. Group B, normal glandular architecture. B. Severe edema in a Langerhans islet, Group BE.

\section{Discussion}

Type 1 Diabetes is a chronic disease with high socioeconomic impact due to its sequelae present in adult life. Its incidence is increasing, transforming this disease in an important public health issue ${ }^{1}$.

Advances in pancreatic transplantation, especially when associated with kidney transplant, have produced encouraging results. Calne et al. ${ }^{16}$ introduced cyclosporine use in clinical practice, improving immunosuppression considerably.

Advances in surgical technique ${ }^{17}$, understandings of cellular events associated with organ rejection, better antibiotic treatments and developments in radiologic imaging ${ }^{18}$ converted kidney-pancreas transplant into first choice treatment for patients with Type 1 Diabetes and end-stage kidney failure ${ }^{5}$.

Nevertheless, the kidney-pancreas transplant continues to have very high complication rates compared to other types of transplant, impacting the total cost of the procedure ${ }^{19}$. Supplies, accounting for about $36 \%$ of costs in our hospital, are one of the most important components of the total price of the procedure. In particular, solutions for perfusion and storage of the donated organs, like the Belzer solution, can be very expensive (around $7 \%$ of total costs), prompting us to evaluate new options for this procedure.

Gonzalez et al. ${ }^{10}$ described the first case series using 1 liter of Euro-Collins solutions, followed by 1 liter of Belzer solution during the perfusion of donated organs, demonstrating no differences in clinical results. Schraibman et al. ${ }^{20}$, using the same technique in rats, also concluded that there were no differences in rates of pancreatic tissue preservation.

Although the feasibility of using a colloid solution like Euro-Collins for the perfusion phase of the procedure has been demonstrated, very few studies have examined whether the use of the Euro-Collins solutions for the storage phase is satisfactory.

Some groups have assessed the use of the Perfluorochemical Oxygen Carrier solution (PFC), expecting to minimize the effects of ischemia during cold storage in animals ${ }^{21,22}$ or humans ${ }^{23,24}$. No differences were found compared to Belzer solution, suggesting that the kind of storage solution might be indifferent in terms of organ preservation.

Amylase values in the storage fluid are related to organ viability, with longer periods of ischemia showing greater release of this enzyme by damaged pancreatic tissue $e^{25,26}$. In our work, no statistically significant differences were observed at six hours of storage comparing three groups (Group B, Belzer solution for perfusion and storage; Group BE, Belzer solution for perfusion, Euro-Collins for storage and Group E, Euro-Collins solution 
for perfusion and storage), suggesting that the amount of tissue injury was similar among groups. On the other hand, amylase values increased both at 12 and $18 \mathrm{~h}$ in groups where the organs were stored in Euro-Collins solution (Groups BE and E). The organs stored in Belzer solution showed no statistically significant increases in amylase values, indicating that, for this group, no significant organ damage was present (Tables 2 and 3).

Furthermore, when analyzing histological parameters that correlate with tissue damage ${ }^{14}$, we found important differences in the exocrine pancreatic tissue from organs stored with the Euro-Collins solution compared to Belzer solution (Table 4 and Figure 1). For the endocrine pancreas, edema was the only finding that was more evident in the Euro-Collins group (Table 5 and Figure 2). Preissler et al. ${ }^{27}$ showed that Langerhans islets are more resistant to ischemia, which could explain why edema was the only histological parameter we found that was different among groups.

\section{Conclusion}

The Euro-Collins solution is inferior to the Belzer solution for the preservation of pancreatic tissue during the cold ischemic storage phase in rats.

\section{References}

1. Georg AE, Duncan BB, Toscano CM, Schmidt MI, Mengue S, Duarte C, Polanczyk CA, Grupo de Trabalho de Avaliação da Campanha Nacional de Detecção de Diabetes Mellitus. Análise econômica de programa para rastreamento do diabetes mellitus no Brasil. Rev Saúde Publica. 2005;39(3):452-60.

2. Kaufman S. Normalization of glucose in the intensive care unit: does one size really fit all? Crit Care Med. 2008;36:2448-9.

3. Kelly WD, Lillehei RC, Merkel FK, Idezuki Y, Goetz FC. Allotransplantation of the pancreas and duodenum along with the kidney in diabetic nephropathy. Surgery. 1967;61:827-37.

4. Sousa MG, Linhares MM, Gonzalez AM, Rangel EB, Melaragno C, Sá JR, Salzedas AA, Nishimi AY, Lopes Filho GJ, Matos D, Pestana JO. Multivariate analysis of risk factors for early loss of pancreas grafts among simultaneous pancreas-kidney transplants. Transplant Proc. 2010;42(2):547-51.

5. Mai ML, Ahsan N, Gonwa T. The long-term management of pancreas transplantation. Transplantation. 2006;82:991-1003.

6. American Diabetes Association. Pancreas transplantation for patients with type 1 diabetes. Diabetes Care. 2000;23 Suppl 1:S85.

7. Wahlberg JA, Love R, Landegaard L, Southard JH, Belzer FO. Successful 72 hours' preservation of the canine pancreas. Transplant Proc. 1987;19:1337-8.

8. Belzer FO. Evaluation of preservation of the intra-abdominal organs. Transplant Proc. 1993;25:2527-30.

9. Uhlmann D, Armann B, Ludwig S, Escher E, Pietsch UC, Tannapfel A, Teupser D, Hauss J, Witzigmann H.Uhlmann, D. Comparison of Celsior and UW solution in experimental pancreas preservation. $\mathrm{J}$ Surg Res. 2002;105(2):173-80.
10. Gonzalez AM, Filho GJ, Pestana JO, Linhares MM, Silva MH, Moura RM, Melaragno C, de Sá JR, Rangel EB, Trivino T. Effects of Eurocollins solution as aortic flush for the procurement of human pancreas. Transplantation. 2005;80(9):1269-74.

11. Cohn JA, Englesbe MJ, Ads YM, Paruch JL, Pelletier SJ, Welling TH, Sonnenday CJ, Magee JC, Punch JD, Campbell DA Jr, Sung RS. Financial implications of pancreas transplant complications: a business case for quality improvement. Am J Tranplant. 2007;7(6):1656-60.

12. Southard JH, Belzer FO. Organ preservation. Ann Rev Med. $1995 ; 46: 235-47$.

13. Howard-Jones N. A CIOMS ethical code for animal experimentation. WHO Chron. 1985;39(2):51-6.

14. Schmidt J, Lewandrowsi K, Warshaw AL, Compton CC, Rattner DW. Morphometric characteristics and homogeneity of a new model of acute pancreatitis in the rat. Int J Pancreatol. 1992;12(1):41-51.

15. Mayer H, Schmidt J, Thies J, Ryschich E, Gebhard MM, Herfarth C, Klar E. Characterization and reduction of ischemia/reperfusion injury after experimental pancreas transplantation. J Gastrointest Surg. 1999;3(2):162-6.

16. Calne RY, Rolles K, White DJ, Thiru S, Evans DB, McMaster P, Dunn DC, Craddock GN, Henderson RG, Aziz S, Lewis P Cyclosporin A initially as the only immunosuppressant in 34 recipients of cadaveric organs: 32 kidneys, 2 pancreases, and 2 livers. Lancet. 1979;2(8151):1033-6.

17. Cook K, Sollinger HW, Warner T, Kamps D, Belzer FO. Pancreaticocystostomy: an alternative method for exocrine drainage of segmental pancreatic allografts. Transplantation. 1983;35:634-6.

18. Kuo PC, Johnson LB, Schweitzer EJ, Bartlett ST. Simultaneous pancreas/kidney transplantation--a comparison of enteric and bladder drainage of exocrine pancreatic secretions. Transplantation. 1997;63:238-43.

19. Humar A, Kandaswamy R, Granger D, Gruessner RW, Gruessner AC, Sutherland DE. Decreased surgical risks of pancreas transplantation in the modern era. Ann Surg. 2000;231(2):269-75.

20. Schraibman V, Goldenberg A, Koh IH, Gonzalez AM, Molinari A, de Morais EC, Artigiani R, Matos D. Evaluation of sequential perfusion with Euro-Collins and Belzer solutions for pancreas preservation in rats. Transplant Proc. 2006;38(9):2780-83.

21. Fujino Y, Kuroda Y, Saitoh Y. Adenine nucleotides metabolism of the canine pancreas during preservation by the two-layer cold storage method. Kobe J Med Sci. 1991;37(6):255-63.

22. Kuroda Y, Tanioka Y, Morita A, Hiraoka K, Matsumoto S, Fujino Y, Yamamoto K, Ku Y, Saitoh Y. Protective effect of preservation of canine pancreas by the two-layer (University of Wisconsin solution/ perfluorochemical) method against rewarming ischemic injury during implantation. Transplantation. 1994;57(5):658-61.

23. Kin T, Mirbolooki M, Salehi P, Tsukada M, O'Gorman D, Imes S, Ryan EA, Shapiro AM, Lakey JR. Islet isolation and transplantation outcomes of pancreas preserved with University of Wisconsin solution versus two-layer method using preoxygenated perfluorocarbon. Transplantation. 2006;82(10):1286-90.

24. Caballero-Corbalán J, Eich T, Lundgren T, Foss A, Felldin M, Källen R, Salmela K, Tibell A, Tufveson G, Korsgren O, Brandhorst D. No beneficial effect of two-layer storage compared with UW-storage on human islet isolation and transplantation. Transplantation. 2007;84(7):864-9.

25. Kinasiewicz A, Fiedor P. Amylase levels in preservation solutions as a marker of exocrine tissue injury and as a prognostic factor for pancreatic islet isolation. Transplant Proc. 2003;35:2345-6.

26. Fiedor P, Goodman ER, Sung RS, Czerwiński J, Rowiński W, Hardy MA. The effect of clinical and biochemical donor parameters on pancreatic islet isolation yield from cadaveric organ donors. Ann Transplant. 1996;1(1):59-62. 
27. Preissler G, Massberg S, Eichhorn ME, Waldner H, Loehe F, Winter $\mathrm{H}, \mathrm{Messmer} \mathrm{K}$. Islets of Langerhans are protected from inflammatory cell recruitment during reperfusion of rat pancreas grafts. Eur Surg Res. 2010;44(3-4):192-200.

\section{Acknowledgements}

To Dr. Debora Romero for performing the histological analyses and Dr. Mariangela Correa for editorial help with the manuscript.

\section{Correspondence:}

Adriano Miziara Gonzalez

Alameda Casa Branca, 471/81

01408-001 São Paulo - SP Brasil

Tel.: (55 11)982229815

amgonzalez@uol.com.br

Received: Nov 14, 2013

Review: Jan 15, 2014

Accepted: Feb 18, 2014

Conflict of interest: none

Financial source: none

${ }^{1}$ Research performed at Laboratory of Development Experimental Models for Medicine and Biology (CEDEME), Sao Paulo Federal University (UNIFESP), Sao Paulo-SP, Brazil. Part of Master degree thesis, Postgraduate Program in Interdisciplinary Surgical Sciences. Tutor: Adriano Miziara Gonzalez 